\title{
NUMERICAL MODELLING OF BREAKER DEPTH INDEX
}

\author{
Felice D’Alessandro ${ }^{1}$, Giuseppe R. Tomasicchio ${ }^{1}$, Giancarlo Chiaia ${ }^{2}$, Francesco Ciardulli ${ }^{3}$, Antonio Francone ${ }^{1}$
}

The breaker depth index, $\gamma_{b}$, is commonly used to determine the wave height to water depth ratio where the wave will break (Horikawa, 1988). In the present study, $\gamma_{b}$ has been calculated using a fully nonlinear Boussinesq Type Equations (BTE) wave model with implemented BCI (Breaking Celerity Index). The BCI is a phase-resolving type breaking criterion for calculating the incipient wave breaking conditions (D'Alessandro and Tomasicchio, 2008). The model suitability in predicting $\gamma_{b}$ has been verified against physical data from an experimental investigation conducted with incident regular waves propagating along uniform 1:20 and 1:50 slope beaches (G.V. dos Reis, 1992), and estimates of $\gamma_{b}$ from five existing empirical formulae (Battjes, 1974; Ostendorf and Madsen, 1979; Singamsetti and Wind, 1980; Smith and Kraus, 1990; Goda, 2010). The comparisons showed that BCI presents a better agreement with the physical data with respect to the other investigated formulae in determining the value of $\gamma_{b}$, independently from the breaker type. In addition, the verification of the $\mathrm{BCI}$ in determining $\gamma_{b}$ has been extended to the observed data from a large-scale laboratory experiment on wave hydrodynamics performed over a fixed-bed barred beach (Tomasicchio and Sancho, 2002).

Keywords: wave breaking; Boussinesq-type equations; breaker depth index; numerical models

\section{INTRODUCTION}

Estimation of wave height transformation due to shoaling and breaking is essential for the nearshore hydrodynamics and the design of coastal structures. When a wave propagates from deep water to shallow region, the wave profile becomes steep and breaks at certain depth. Many theories and empirical formulae for the calculation of wave shoaling and the prediction of breaking have been proposed in literature.

The criteria for incipient wave breaking in terms of breaking height and breaking depth have been analyzed by many investigators, such as McCowan (1894), Miche (1944), Munk (1949), Battjes (1974), Goda (1974), Ostendorf and Madsen (1979), Singamsetti and Wind (1980), Peregrine (1983), Smith and Kraus (1990), Rattanapitikon and Shibayama (2000), Camenen and Larson (2007), Goda (2010). Most of them considered wave propagation along gentle slope beaches. Some questions still remain open for steep slope beaches where the reflection has a large influence on the wave-structure interaction (Brunone and Tomasicchio, 1997; Kobayashi et al., 2000).

The advances in computer sciences have allowed to use the phase-resolving Boussinesq-type equations (BTE) models for near-shore wave transformations (Peregrine, 1967; Madsen et al., 1991; Nwogu, 1993; Wei et al., 1995). However, in the original form, the BTE do not consider the physics of wave breaking and thus become invalid in the surf zone. Accordingly, there have been attempts to introduce wave breaking into BTE. In BTE models, the incipient wave breaking condition is given by an external trigger mechanism. There are two types of phase-resolving wave breaking triggers to determine the initiation/cessation of the process. Both triggers are controlled by the free surface kinematics: the slope angle variation (Schäffer et al., 1993), or the vertical speed of the free surface elevation (Kennedy et al., 2000). Both adopt three parameters to determine the critical conditions, which are the initiation condition, the termination condition, and the duration time. The three coefficients are somewhat hypothetical to match numerical results to experimental data, therefore, they have to be changed according to the expected breaker type and the bathymetrical setting. An improvement respect to the three parameters trigger mechanisms has been introduced with the Breaking Celerity Index (BCI) (D’Alessandro and Tomasicchio, 2008).

\section{THE BREAKER DEPTH INDEX} ratio:

The breaker depth index, $\gamma_{\mathrm{b}}$, is defined as the limiting breaker height, $H_{\mathrm{b}}$, to breaking depth, $h_{\mathrm{b}}$,

$$
\gamma_{b}=\frac{H_{b}}{h_{b}}
$$

By referring to the types of the breaker depth index formulae analyzed by Kamphuis (1991), their functional forms can be classified into the following:

\footnotetext{
${ }^{1}$ Department of Engineering, University of Salento, Ecotekne, Via Monteroni, 73100 Lecce, Italy

${ }^{2}$ DICATECh, Technical University of Bari, Via E. Orabona, 70126 Bari, Italy

${ }^{3}$ CWP Engineering - Marina Plaza, Dubai Marina, Dubai, United Arab Emirates
} 


$$
\begin{gathered}
H_{b} / h_{b}=f_{1}(0)=\text { constant } \\
H_{b} / h_{b}=f_{2}\left(h_{b} / L_{0} \text { or } h_{b} / L_{b}\right) \\
H_{b} / h_{b}=f_{3}(m) \\
H_{b} / h_{b}=f_{4}\left(m, H_{0} / L_{0}\right) \\
H_{b} / h_{b}=f_{5}\left(m, h_{b} / L_{0} \text { or } h_{b} / L_{b}\right)
\end{gathered}
$$

where $H_{0} / L_{0}=$ deep water wave steepness and $m=$ beach slope. Because the relative water depth $h_{\mathrm{b}} / L_{0}$ is easily converted to $h_{\mathrm{b}} / L_{\mathrm{b}}$ through the dispersion relationship, the two relative depths, $h_{\mathrm{b}} / L_{0}$ and $h_{\mathrm{b}} / L_{\mathrm{b}}$, are interchangeable.

The earliest data on wave breaking were provided by Iversen (1953), who presented four tables and diagrams of breaking wave statistics on the beach slopes of 1/10,1/20,1/30, and 1/50. Then, several datasets on breaking wave statistics have become available (Kishi and Iohara, 1958; Goda, 1964; Galvin 1969; Li et al., 1991; Lara et al., 2006). By using the datasets available at that time, Goda (1970) prepared the diagrams of breaker depth index for four beach slopes of $1 / 10,1 / 20,1 / 30$ and $1 / 100$ by referring to the theoretical limiting wave heights on the horizontal bed calculated by Yamada and Shiotani (1968). Then, Goda (1974) converted the graphical curves of his breaker depth index into a functional form of the following for convenience of wave pressure computation of composite breakwaters:

$$
\gamma_{b}=A \frac{L_{0}}{h_{b}}\left\{1-\exp \left[-1.5 \pi \frac{h_{b}}{L_{0}}\left(1+15 m^{4 / 3}\right)\right]\right\} \quad: A=0.17
$$

Studies on breaking wave statistics have continued through the 1970s to 1990s. Many different formulae have been proposed based on monochromatic wave experiments. Smith and Kraus (1990) and Rattanapitikon and Shibayama (2000) compared some of these formulae with data. It appeared that the main governing factors for the breaker depth index are $m$ and $H_{0} / L_{0}$.

In the present study, five formulae have been investigated:

- $\quad$ Battjes (1974)

$$
\gamma_{b}=1.062-0.137 \log \xi_{0}
$$

with $\xi_{0}=m / \sqrt{H_{0} / L_{0}}$

- $\quad$ Ostendorf and Madsen (1979)

$$
\gamma_{b}=0.14 \frac{L_{b}}{h_{b}} \tanh \left[(0.8+5 \min (m, 0.1)) \frac{2 \pi h_{b}}{L_{b}}\right]
$$

- $\quad$ Singamsetti and Wind (1980)

$$
\gamma_{b}=0.937 m^{0.155}\left(\frac{H_{0}}{L_{0}}\right)^{-0.13}
$$

- $\quad$ Smith and Kraus (1990)

$$
\gamma_{b}=\frac{1.12}{1+\exp (-60 m)}-5.0[1+\exp (-43 m)] \frac{H_{0}}{L_{0}}
$$

- $\quad$ Goda (2010) 


$$
\gamma_{b}=A \frac{L_{0}}{h_{b}}\left\{1-\exp \left[-1.5 \pi \frac{h_{b}}{L_{0}}\left(1+11 m^{4 / 3}\right)\right]\right\}
$$

With reference to Eq. (7), Rattanapitikon and Shibayama (2000) recommended a modification of the slope effect term of $\left(1+15 \mathrm{~m}^{4 / 3}\right)$ into $\left(1.033+4.71 \mathrm{~m}-10.46 \mathrm{~m}^{2}\right)$. Upon re-examination of the original laboratory data, Goda (2010) proposed a new modification of the slope effect term. The revision has been made to replace the slope effect term with $\left(1+11 \mathrm{~m}^{4 / 3}\right)$ as reported in Eq. (12). Therefore, it should be noticed that Eqs. 7, 9 and 12 require an iterative technique, whereas Eqs. 8, 10 and 11 allow for a direct computation.

\section{THE BREAKING CELERITY INDEX}

The Breaking Celerity Index (D’Alessandro and Tomasicchio, 2008) is obtained by coupling two different existing trigger mechanisms: the criterion proposed by Kennedy et al. (2000) and the Relative Trough Froude Number Theory (RTFN) (Utku, 1999; Okamoto and Basco, 2006). In particular, following Kennedy et al. (2000), the vertical speed of the free surface elevation, $\eta_{\mathrm{t}}$, is computed and compared, with a controlling parameter which is called BCI. Similarly to Kennedy et al. (2000), wave breaking occurs when $\eta_{\mathrm{t}}$ exceeds the initial threshold value BCI, which is given as:

$$
B C I=\frac{\sqrt{g(h+a)}-u_{\alpha}}{1.47}
$$

where $u_{\alpha}=$ horizontal velocity component at a reference water depth $z=z_{\alpha}=-0.531 h$ (Nwogu, 1993), $h$ = water depth, $a=$ wave amplitude at breaking. It has been demonstrated that use of $u_{\alpha}$, with optimal choice of $z_{\alpha}=-0.531 h$ (Nwogu, 1993), improves the linear dispersion property in intermediate water depth and makes the range of validity for the extended Boussinesq models (Nwogu, 1993; Wei et al., 1995) larger than for that the standard Boussinesq model (Peregrine, 1967). Liu and Losada (2002) stated that it is straightforward to show that the conventional Boussinesq equations (Peregrine, 1967), and the modified Boussinesq equations (Nwogu, 1993) are the subsets of the fully nonlinear BTE (e.g. Wei et al., 1995).

At each grid node and for each time step, the BTE model solves the depth integrated equations for the free surface elevation, $\eta$, and $u_{\alpha}$. Consequently, $\eta_{\mathrm{t}}$, is computed and compared with BCI. The breaking event starts when/where $\eta_{\mathrm{t}}>\mathrm{BCI}$. With respect to the other breaking criteria (Schäffer et al., 1993; Kennedy et al., 2000, Utku, 1999; Okamoto and Basco, 2006), the BCI eliminates the uncertainties on the values of parameters to be calibrated also decreasing the CPU time in the calculation run resulting in a practical relevant advantage (D'Alessandro and Tomasicchio, 2008).

\section{THE NUMERICAL MODEL}

The 1D-FUNWAVE (Fully Nonlinear Boussinesq WAVE) model has been used in the applications. It has been proposed and developed at the University of Delaware (USA) (Kirby et al., 1998). The governing equations of the model are based on the fully nonlinear BTE derived by Wei et al. (1995). The Boussinesq model solves the depth integrated equations for $\eta$ and $u_{\alpha}$. To enable the Boussinesq model to simulate surf zone hydrodynamics, energy dissipation due to wave breaking is modeled by introducing an eddy viscosity term into the momentum equation, with the viscosity strongly localized on the front face of the breaking waves (Kennedy et al., 2000). Wave runup on the beach is simulated using a permeable-seabed technique. FUNWAVE considers a source function to generate monochromatic and random waves. Sponge layers are placed at the ends of the domain to effectively damp the energy of outgoing waves with different frequencies and directions. The model utilizes a fourth-order predictor-corrector method to advance in time, and solves first order spatial derivatives to fourth-order accuracy.

\section{MODEL VERIFICATION}

The present study aims to verify the suitability of a BTE model with implemented BCI in predicting the breaker depth index for a breaking wave over uniform slope and barred beaches.

\section{Uniform slope beach}

The model suitability in predicting $\gamma_{b}$ has been verified against physical data from a small-scale experimental investigation conducted with incident regular waves propagating along uniform 1:20 and 1:50 slope beaches, covering both spilling and plunging breaker types (G.V. dos Reis, 1992), and 
estimates of $\gamma_{\mathrm{b}}$ from five existing empirical formulae (Battjes, 1974; Ostendorf and Madsen, 1979; Singamsetti and Wind, 1980; Smith and Kraus, 1990; Goda, 2010).

Simulations have been performed by 1D-FUNWAVE model (Kirby et al., 1998) referring to the nonlinear BTE of Wei et al. (1995) after altering the subroutine for incipient wave breaking with the BCI trigger mechanism (D'Alessandro and Tomasicchio, 2008). The numerical model computed the incipient wave breaking characteristics: $x_{b}=$ breaking initiation location with the corresponding $h_{b}$. The wave breaking initiation location has been defined as the horizontal distance from the toe of the beach slope to the wave crest location where the wave breaking event occurred. The value of $H_{b}$ has been obtained as averaged wave height from the calculated time series of $\eta$ at $x_{b}$.

The experimental longitudinal laboratory beach profile at University of Liverpool presented a flat horizontal bottom with still water depth, $h_{0}$, followed by a uniform slope. Table 1 summarizes the simulated experimental characteristics with the corresponding offshore wave conditions, where $H_{0}=$ wave height and $T=$ wave period.

\begin{tabular}{|c|c|c|c|c|}
\hline \multicolumn{6}{|l|}{ Table 1. Simulated experimental characteristics } \\
\hline Data set & $m$ & $h_{0}(\mathrm{~m})$ & $H_{0}(\mathrm{~m})$ & $T(\mathrm{~s})$ \\
\hline \multirow{2}{*}{ G.V. dos Reis (1992) } & $1: 20$ & 0.2 & $0.015 \div 0.070$ & $0.7 \div 1.5$ \\
\cline { 2 - 5 } & $1: 50$ & 0.2 & $0.015 \div 0.066$ & $0.7 \div 1.5$ \\
\hline
\end{tabular}

Figures 1 and 2 show the comparisons among the observed, calculated by BCI, and estimated values of $\gamma_{b}$ as a function of deep water wave steepness, $H_{0} / L_{0}$, for the cases of 1:20 and 1:50 beach slopes, respectively.

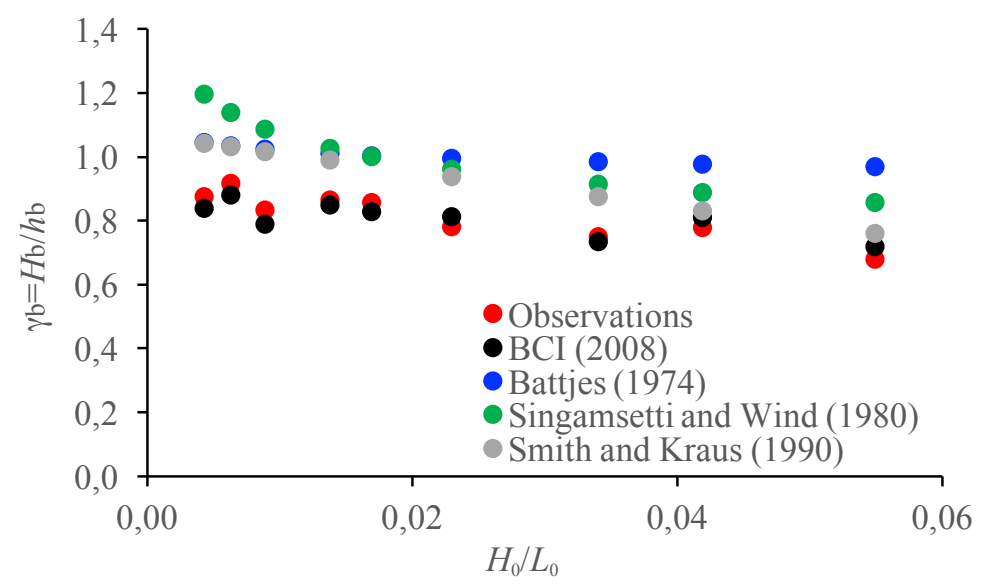

Figure 1. The ratio $Y_{b}=H_{b} / h_{b}$ as a function of the deep water wave steepness, $H_{0} / L_{0}$. Comparison among observations, $\mathrm{BCl}$ criterion and empirical formulae. Slope 1:20.

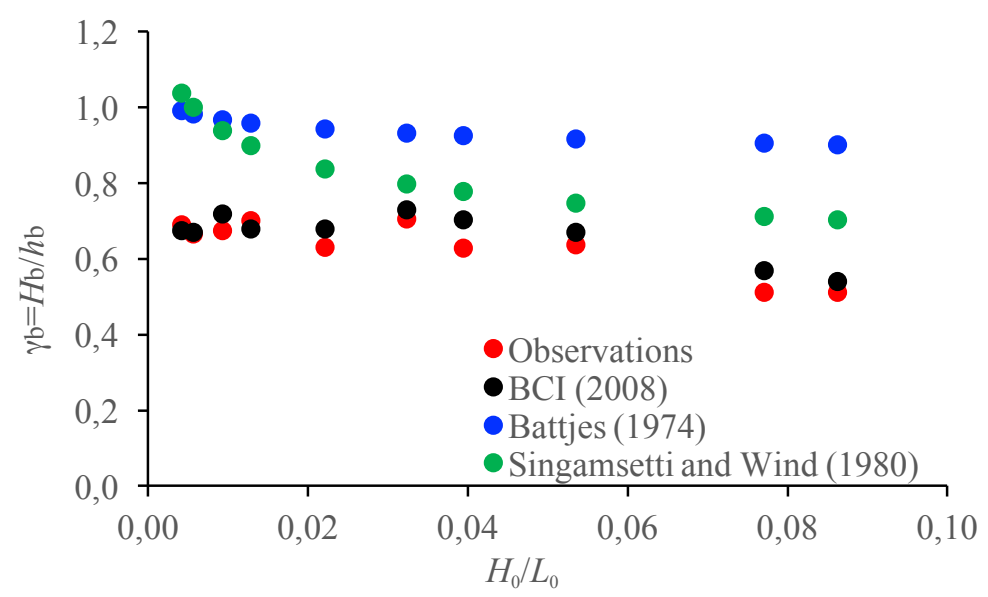

Figure 2. The ratio $Y_{b}=H_{b} / h_{b}$ as a function of the deep water wave steepness, $H_{0} / L_{0}$. Comparison among observations, $\mathrm{BCl}$ criterion and empirical formulae. Slope 1:50. 
With regard to the dependence of $\gamma_{b}$ on the deep water wave steepness, main results can be summarized as in the following:

- the observed data indicated values of $\gamma_{b}$ that are nearly independent from $\sqrt{H_{0} / L_{0}}$. Only for the 1:50 slope case, a certain decrease in $\gamma_{\mathrm{b}}$ for higher values of $\sqrt{H_{0} / L_{0}}$ has been obtained;

- a decrease in $\gamma_{\mathrm{b}}$ with an increase in $\sqrt{H_{0} / L_{0}}$ appeared clearer and quite pronounced for the Singamsetti and Wind (1980) and Smith and Kraus (1990) formulae; Battjes (1974) formula and BCI did not present the same behavior in comparison with the other formulae;

- both for slope 1:20 and 1:50, Battjes (1974), Singamsetti and Wind (1980) and Smith and Kraus (1990) formulae generally overestimated the observed breaker depth index. It is noticed that for the case of 1:50 slope, Smith and Kraus (1990) formula has not been included in the comparisons since, on the basis of the original empirical data, it covers a range of $0.03<m<$ 0.44 excluding the investigated beach slope of 1:50;

- $\quad$ BCI predictions of $\gamma_{b}$ showed the best agreement with the observations, capturing the observed behavior of $\gamma_{b}$ as a function of the deep water wave steepness.

In addition, the BCI suitability in determining $\gamma_{b}$ has been also verified with reference to the empirical formulae proposed by Goda (2010) and Ostendorf and Madsen (1979).

Figures 3 and 4 show the comparisons among the values of $\gamma_{b}$ observed, calculated by BCI, and estimated by Goda (2010) and Ostendorf and Madsen (1979) formulae, as a function of $h_{b} / L_{o}$, for the case of 1:20 and 1:50 beach slopes, respectively.

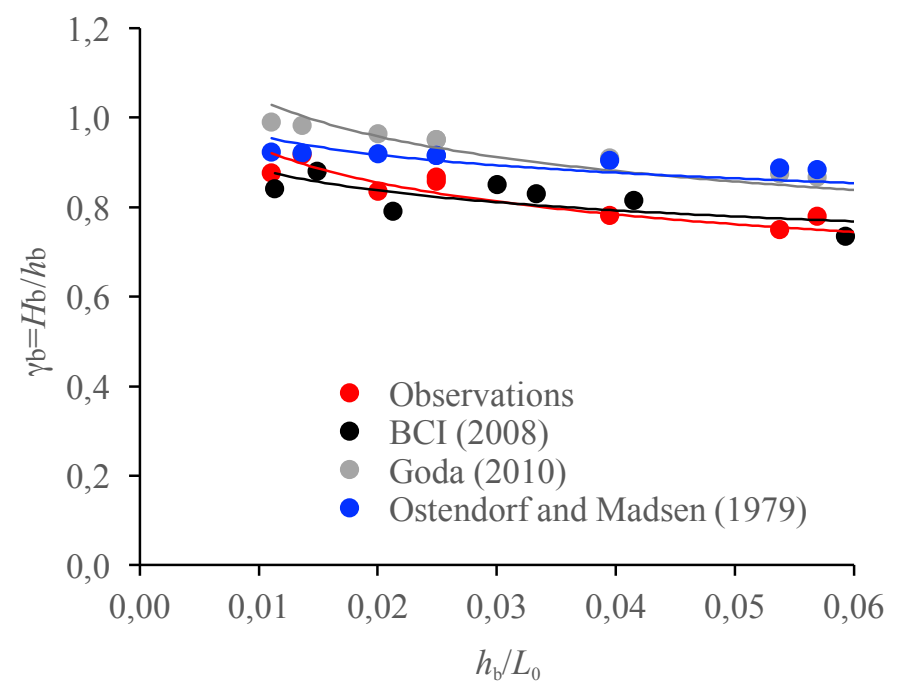

Figure 3. Breaker index, $y_{b}$, versus $h_{b} / L_{o}$. Comparison among observations, $\mathrm{BCl}$ criterion and empirical formulae. Slope 1:20.

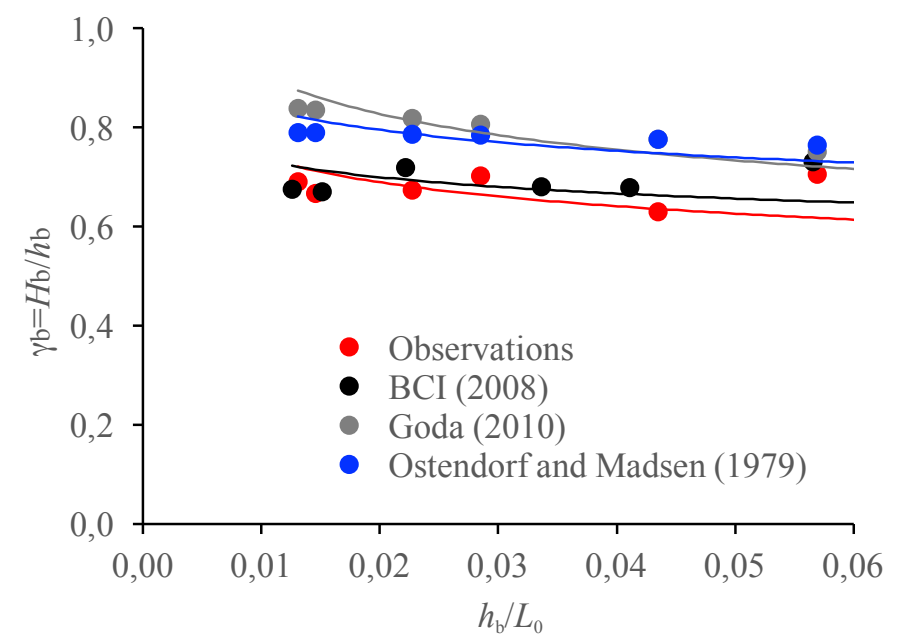

Figure 4. Breaker index, $Y_{b}$, versus $h_{b} / L_{o}$. Comparison among observations, $B C l$ criterion and empirical formulae. Slope 1:50. 
Comparison of the results shown in Figures 3 and 4 revealed that the BCI criterion exhibited the best agreement with observations compared with the two investigated formulae followed by, in order, Ostendorf and Madsen (1979) and Goda (2010). For both beach slope cases it has been shown that the value of the breaker depth index slightly decreased with an increase of $h_{b} / L_{o}$.

The modification of the slope effect term into Goda's (1974) formula proposed by Rattanapitikon and Shibayama (2000) has been also considered in the comparisons. The obtained results of $\gamma_{b}$ showed a lower agreement with the observations respect to Goda's (2010) formula predictions. These results are not included in this paper.

\section{Barred beach}

This section of study intends to assess the capability of BCI in determining $\gamma_{b}$ for a breaking wave over a barred beach at quasi field conditions. The verification has considered data from a large-scale laboratory experiment on wave hydrodynamics performed over a fixed-bed barred beach at the CIEM wave flume of the Polytechnic University of Catalonia, which is $100 \mathrm{~m}$ long, $3 \mathrm{~m}$ wide and $5 \mathrm{~m}$ deep (Tomasicchio and Sancho, 2002). Three sets of regular wave conditions (designated as tests A, B and $\mathrm{C}$, respectively) and one irregular sea-state (test D) have been considered in the experiments. Table 2 summarizes the adopted wave conditions with $H_{\mathrm{rms}}=$ root mean square wave height in front of the wave-maker, $T_{\mathrm{p}}=$ peak wave period, $L=$ computed wavelength at the wave-maker (using linear theory) and the observed $x_{\mathrm{b}}, H_{\mathrm{b}}$, and $h_{\mathrm{b}}$.

\begin{tabular}{|c|c|c|c|c|c|c|c|}
\hline \multicolumn{1}{|c|}{ Table 2. Characteristics of the adopted wave conditions } \\
\hline Wave condition & $H_{\mathrm{rms}}(\mathrm{m})$ & $T_{\mathrm{p}}(\mathrm{s})$ & $H_{\mathrm{rms}} / \mathrm{L}$ & $x_{\mathrm{b}}(\mathrm{m})$ & $H_{\mathrm{b}}(\mathrm{m})$ & $h_{\mathrm{b}}(\mathrm{m})$ & Breaking type \\
\hline $\mathrm{A}$ & 0.21 & 2.50 & 0.024 & 45.5 & 0.30 & 0.41 & Spilling \\
\hline $\mathrm{B}$ & 0.21 & 3.50 & 0.015 & 44.0 & 0.35 & 0.45 & Plunging \\
\hline $\mathrm{C}$ & 0.38 & 3.50 & 0.027 & 39.5 & 0.58 & 0.56 & Plunging \\
\hline $\mathrm{D}$ & 0.21 & 2.50 & 0.024 & 41.0 & 0.23 & 0.51 & Both \\
\hline
\end{tabular}

A value of the estimated breaker-depth index for each test has been determined according to Battjes and Stive (1985) by:

$$
\gamma_{b}=0.5+p \cdot \tanh \left(33 \frac{H_{r m s, 0}}{L_{0}}\right)
$$

with $H_{\text {rms }, 0}$ and $L_{0}$ deep water values (using linear wave shoaling for peak frequency) of the root mean square wave height and wave length and $p=0.4 \div 0.5$ (Sancho, 2002). Table 3 shows the values of $\gamma_{\mathrm{b}}$ obtained with Eq. (14) (Sancho, 2002) together with the local values at breaking point of the normalized wave height, $H_{\mathrm{rms}} / h$, observed and calculated with BCI.

\begin{tabular}{|c|c|c|c|}
\hline Wave condition & $\gamma_{\mathrm{b}}$ (Battjes and Stive, 1985) & $\left(H_{\text {rms }} / h\right)_{\text {observed }}$ & $\left(H_{\text {rms }} / h\right)_{\text {calculated }}$ \\
\hline $\mathrm{A}$ & 0.77 & 0.71 & 0.67 \\
\hline $\mathrm{B}$ & 0.66 & 0.74 & 0.77 \\
\hline $\mathrm{C}$ & 0.76 & 0.94 & 0.77 \\
\hline $\mathrm{D}$ & 0.76 & 0.55 & 0.53 \\
\hline
\end{tabular}

Figure 5 shows the cross-shore variation of $\mathrm{H}_{\mathrm{rms}} / h$ as a function of the normalized breaking position $\left(x / x_{\mathrm{b}}\right)$.

In general, the measured and calculated values of $H_{\mathrm{rms}} / h$ at $x=x_{\mathrm{b}}$ did not coincide with the estimates

of $\gamma_{b}$. Therefore, for test $C$, the calculated value showed a better agreement with corresponding $\gamma_{b}$ with respect to the observation although the calculated local maximum of $H_{\mathrm{rms}} / h$ occurred slightly shoreward with respect to the measured $x_{\mathrm{b}}$. The maximum values of $H_{\mathrm{rms}} / h$ at the breaking point for tests $\mathrm{B}$ and $\mathrm{C}$ were slightly larger than for test A. These differences highlighted distinctions in the wave breaking process: wave in tests $\mathrm{B}$ and $\mathrm{C}$ were plunging breakers, whereas waves in test A were spilling breakers (Sancho, 2002). For the random wave D, the maximum calculated value of $H_{\mathrm{rms}} / h$, at the first breaking position, was approximately equal to 0.53 which was close to the observation and it was below the value of $\gamma_{\mathrm{b}}=0.76$ also occurring slightly shoreward with respect to the measured $x_{\mathrm{b}}$ in accordance with 
case C. Near to the shore, despite the large scatter due to difficulties in measuring water depths within the swash zone, $H_{\text {rms }} / h$ appeared to increase monotically for all tests, in agreement with Kobayashi et al. $(1997,1998)$.
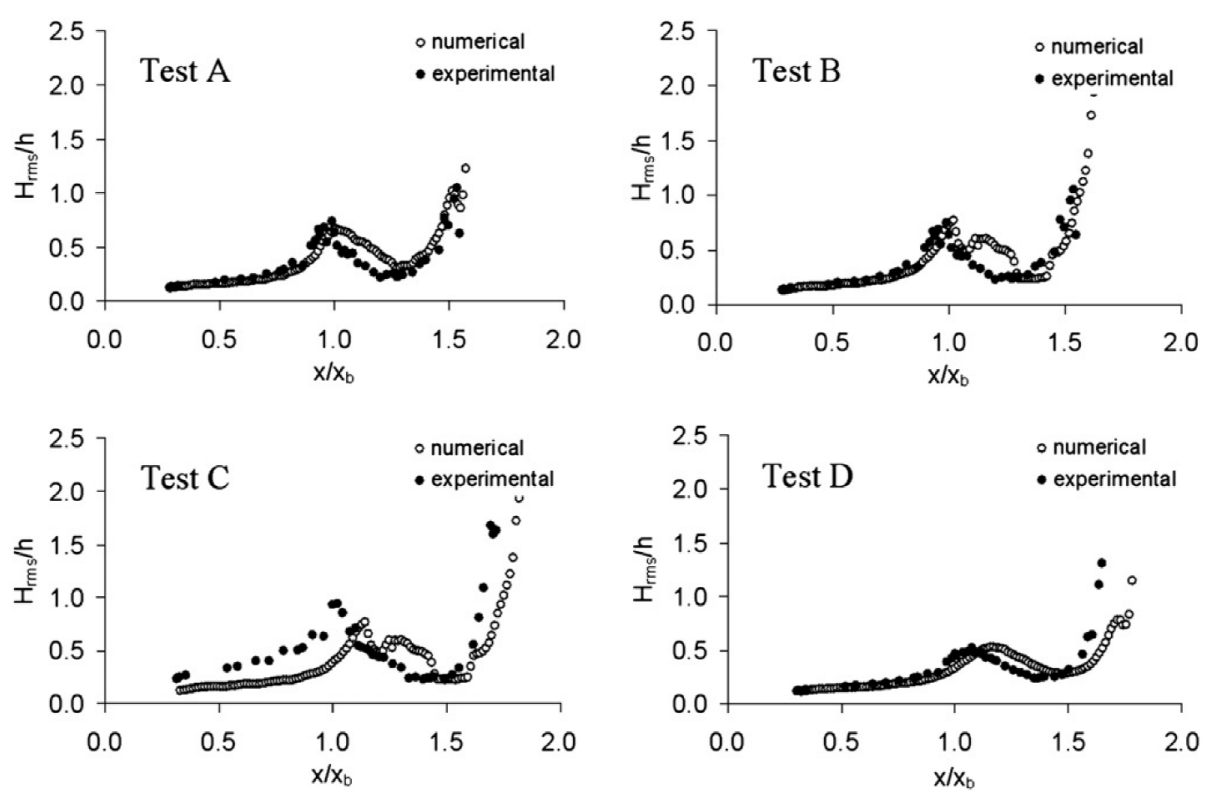

Figure 5. Dimensionless cross-shore variation of $\boldsymbol{H}_{\mathrm{rms}} / \boldsymbol{h}$ for tests A-D.

\section{CONCLUSIONS}

The incipient wave breaking conditions of regular and irregular waves at gentle slope and barred beaches have been computed using a fully nonlinear BTE wave model (Wei et al., 1995) with implemented BCI. Characteristics of waves have been calculated at the breaking point and the breaker depth index has been determined.

For the uniform slope beach case, the main results are summarized as in the following:

- the observed data indicated values of $\gamma_{b}$ that were nearly independent of $\sqrt{H_{0} / L_{0}}$. Only for the 1:50 slope case, a certain decrease in $\gamma_{\mathrm{b}}$ for higher values of $\sqrt{H_{0} / L_{0}}$ has been obtained;

- a decrease in $\gamma_{b}$ with an increase in $\sqrt{H_{0} / L_{0}}$ appeared clearer and quite pronounced for the Singamsetti and Wind (1980) and Smith and Kraus (1990) formulae; Battjes (1974) formula and BCI did not present the same behavior in comparison with the other investigated formulae;

- both for slope 1:20 and 1:50, Battjes (1974), Singamsetti and Wind (1980) and Smith and Kraus (1990) formulae generally overestimated the observed breaker depth index. It is noticed that for the case of 1:50 slope, Smith and Kraus (1990) formula has not been included in the comparisons since, on the basis of the original empirical data, it covers a range of $0.03<m<$ 0.44 excluding the investigated beach slope of 1:50;

- $\quad$ BCI predictions of $\gamma_{b}$ showed the best agreement with the observations, capturing the observed behavior of $\gamma_{b}$ as a function of the deep water wave steepness;

- $\quad$ BCI suitability in determining the breaker depth index has been also verified with reference to the empirical formulae proposed by Goda (2010) and Ostendorf and Madsen (1979). Comparisons revealed that the BCI criterion exhibited the best agreement with observations compared with the two investigated formulae followed by, in order, Ostendorf and Madsen (1979) and Goda (2010). For both beach slope cases it has been shown that the value of the breaker depth index slightly decreased with an increase of $h_{b} / L_{o}$.

In addition, the verification of the BCI in determining $\gamma_{\mathrm{b}}$ has been extended to the observed data from a large-scale laboratory experiment on wave hydrodynamics performed over a fixed-bed barred beach (Tomasicchio and Sancho, 2002).

In general, the measured and calculated values of $H_{\mathrm{rms}} / h$ at $x=x_{\mathrm{b}}$ did not coincide with the estimates of $\gamma_{b}$. Therefore, for test $\mathrm{C}$, the calculated value showed a better agreement with corresponding $\gamma_{\mathrm{b}}$ with respect to the observation although the calculated local maximum of $H_{\mathrm{rms}} / h$ occurred slightly shoreward with respect to the measured $x_{\mathrm{b}}$. The maximum values of $H_{\mathrm{rms}} / h$ at the 
breaking point for tests $\mathrm{B}$ and $\mathrm{C}$ were slightly larger than for test $\mathrm{A}$. These differences highlighted distinctions in the wave breaking process: wave in tests $\mathrm{B}$ and $\mathrm{C}$ were plunging breakers, whereas waves in test A were spilling breakers (Sancho, 2002). For the random wave D, the maximum calculated value of $H_{\mathrm{rms}} / h$, at the first breaking position, was approximately equal to 0.53 which was close to the observation and it was below the value of $\gamma_{b}=0.76$ also occurring slightly shoreward with respect to the measured $x_{\mathrm{b}}$ in accordance with case $\mathrm{C}$. Near to the shore, despite the large scatter due to difficulties in measuring water depths within the swash zone, $H_{\mathrm{rms}} / h$ appeared to increase monotically for all tests, in agreement with Kobayashi et al. (1997, 1998).

It has been found that the experiment conducted at CIEM wave flume (Tomasicchio and Sancho, 2002) has offered the ideal conditions to study wave-induced kinematics at a quasi prototype-scale environment confirming the BCI effectiveness in determining $\gamma_{\mathrm{b}}$ also in the presence of a bar.

\section{REFERENCES}

Battjes, J. 1974. Surf similarity, Proceedings $14^{\text {th }}$ Int. Conf. Coastal Engineering, Copenhagen, ASCE, 1050-1061.

Battjes, J.A., M.J.F. Stive. 1985. Calibration and verification of a dissipation model for random breaking waves, Journal of Geophysical Research 90(C5), 9159-9167.

Brunone, B., G.R. Tomasicchio. 1997. Wave kinematics at steep slopes: Second-order model. Journal of Waterway, Port, Coastal and Ocean Engineering, 123, 223-232.

Camenen, B., and M. Larson. 2007. Predictive formulas for breaker depth index and breaker type, Journal of Coastal Research, 23(4), 1028-1041.

D’Alessandro, F., G.R. Tomasicchio. 2008. The BCI criterion for the initiation of breaking process in Boussinesq type equations wave models, Coastal Engineering, 55, 1174-1184.

Galvin, C.J.Jr. 1969. Breaker travel and choice of design wave height, Journal of Waterways and Harbors Div., ASCE, 95 (WW2): 175-200.

Goda, Y. 1964. Wave forces on a vertical circular cylinder: experiments and proposed method of wave force computation, Report Port and Harbour Res. Inst., 8: 1-74.

Goda, Y. 1970. A synthesis of breaker indices, Trans. Jap. Soc. of Civil Engineers, 2, 39-49.

Goda, Y. 1974. New wave pressure formulae for composite breakwaters, Proceedings $14^{\text {th }}$ Int. Conf. Coastal Engineering, Copenhagen, ASCE, 1702-1720.

Goda, Y. 2010. Reanalysis of regular and random breaking wave statistics, Coastal Engineering Journal, 52(1), 71-106.

Gonsalves Veloso dos Reis, M.T.L. 1992. Characteristics of waves in the surfzone, MS Thesis, Department of Civil Engineering, University of Liverpool, Liverpool.

Horikawa, K. 1988. Nearshore Dynamics and Coastal Processes, Theory, Measurement and Predictive Models, University of Tokyo Press, Tokyo, Japan.

Iversen, H.W. 1951. Laboratory study of breakers, Gravity Waves Proc. NBS Semicentennial Symp., NBS Circular 521: 9-32.

Kamphuis, J.W. 1991. Incipient wave breaking, Coastal Engineering, 15, 185-203.

Kennedy, A.B., Q. Chen, J.T. Kirby, and R.A. Dalrymple. 2000. Boussinesq modeling of wave transformation, breaking and run-up. I: 1D, Journal of Waterway, Port, Coastal and Ocean Engineering, 126, 39-47.

Kirby, J.T., G. Wei, Q. Chen, A.B. Kennedy, and R.A. Dalrymple. 1998. FUNWAVE 1.0 Fully Nonlinear Boussinesq Wave Model Documentation and User's Manual, Research Report No CACR98-06, Center for Applied Coastal Res., University of Delaware, Newark.

Kishi, T., and S. Iohara. 1958. Researches on coastal dikes (7) - experimental study on wave transformation and breaking waves, Rept. Public Works Res. Inst., 95: 185-197 (in Japanese).

Kobayashi, N., M.D. Orzech, B.D. Johnson, M.N. Herrman. 1997. Probability modeling of surf zone and swash dynamics, Proceedings Int. Symp. on Ocean Wave Measurement and Analysis - Waves' 97. ASCE, Reston, VA, pp. 107-121.

Kobayashi, N., M.N. Herrman, B.D. Johnson, M.D. Orzech. 1998. Probability distribution of surface elevation in surf and swash zones, Journal of Waterway, Port, Coastal and Ocean Engineering, ASCE 124(3), 99-107.

Kobayashi, N., G.R. Tomasicchio, B. Brunone. (2000). Partial standing waves at a steep slope, Journal of Coastal Research, 16(2), pp. 379-384.

Lara, J.L., I.J. Losada, and P. L.-F. Liu. 2006. Breaking waves over a mild gravel slope: Experimental and numerical analysis, J. Geophys. Res., 111 (C11019), 1-26. 
Li, Y.C., G.H. Dong, and B. Teng. 1991. Wave breaker indices in finite water depth, China Ocean Engineering, 5 (1): 51-64.

Liu, P.L.-F., I.J. Losada. 2002. Wave propagation modeling in coastal engineering, Journal of Hydraulic Research, 40(3), 229-240.

Madsen, P.A., R. Murray, and O.R. Sørensen. 1991. A new form of the Boussinesq equations with improved linear dispersion characteristics, Coastal Engineering, 15, 371-388.

McCowan, J. 1894. On the highest waves in water, Phil. Mag. Ser., 5, 36: 351-358.

Miche, R. 1944. Mouvements ondulatoires de l'ocean pour une eau profonde constante et d'ecroissante, Ann. des Ponts et Chaussèes, 25-78, 131-164, 270-292, 369-406.

Munk, W.H. 1949. The solitary wave theory and its applications to surf problem, Ann. New York Acad. Sci., 51: 376-423.

Nwogu, O. 1993. Alternative form of Boussinesq equations for nearshore wave propagation, Journal of Waterway, Port, Coastal and Ocean Engineering, 119, 618-638.

Okamoto, T., and D.R. Basco. 2006. The Relative Trough Froude Number for initiation of wave breaking: Theory, experiments and numerical model confirmation, Coastal Engineering, 53, 675690.

Ostendorf, D., and O. Madsen. 1979. An analysis of longshore current and associated sediment transport in the surf zone, Technical Report no 241, Dep. Civil Eng., MIT, USA, 169.

Peregrine, D.H. 1967. Long waves on a beach, Journal of Fluid Mechanics, 27(4), 815-827.

Peregrine, D.H. 1983. Breaking waves on beaches, Annu. Rev. Fluid Mech., 15: 149-178.

Rattanapitikon, W. and T. Shibayama. 2000. Verification and modification of breaker height formulas, Coastal Engineering Journal, 42(4), 389-406.

Sancho, F. 2002. Surface wave statistics past a barred beach, Proceedings of $6 t^{h}$ Congress of SIMAI, Chia Laguna.

Schäffer, H.A., P.A. Madsen, and R. Deigaard. 1993. A Boussinesq model for waves breaking in shallow water, Coastal Engineering, 20, 185-202.

Singamsetti, S. and H. Wind. 1980. Characteristics of breaking and shoaling periodic waves normally incident on to plane beaches of constant slope, Technical Report M1371, Delft Univ. Tech., The Netherlands.

Smith, J.W., and N.C. Kraus. 1991. Laboratory study of wave-breaking over bars and artificial reefs. Journal of Waterway, Port, Coastal, and Ocean Engineering, ASCE, 117(4): 307-325.

Tomasicchio, G.R., F. Sancho. 2002. On wave induced undertow at a barred beach, Proceedings of 28th International Conference on Coastal Engineering, ASCE, pp. 557-569.

Utku, M. 1999. The Relative Trough Froude Number. A new criteria for wave breaking, Ph.D. Dissertation, Dept. of Civil and Enviromental Engineering, Old Dominion University, Norfolk, VA.

Van Rijn, L. 1990. Principles of fluid flow and surface waves in river, estuaries, seas and ocean. Aqua Publications, The Netherlands.

Yamada, H., and T. Shiotani. 1968. On the highest water waves of permanent type. Bull. Disaster Prevention Res. Inst., Kyoto Univ., 18-2(135): 1-22.

Wei, G., J.T. Kirby, S.T. Grilli, and R. Subramanya. 1995. A fully nonlinear Boussinesq model for surface waves. I: highly non linear, unsteady waves. Journal of Fluid Mechanics, 294, 71-92. 